\title{
About the Benefits of Pleasure-in-Others'-Misfortune. Aaron Ben-Ze'ev's Depiction of Emotions as Adaptive Mechanisms
}

\author{
Magdalena Michalik-Jeżowska \\ University of Rzeszow, Poland \\ e-mail: wjwj1@o2.p1
}

\begin{abstract}
:
This paper was inspired by two ideas: (1) the concept of emotions as adaptive mechanisms, which was suggested by Aaron Ben-Ze'ev, and (2) Robert Solomon's criticism of the distinction between "positive" and "negative" emotions which functions in social sciences. In the context of the above mentioned theoretical perspectives I consider the infamous emotion of pleasure-in-others'-misfortune in terms of possible benefits for the experiencing subject. I focus especially on supposed adaptive quality of pleasure-in-others'-aging.

Keywords: emotion, pleasure-in-others'-misfortune, pleasure-in-others'-aging, adaptation, aging, Schadenfreude.
\end{abstract}

\section{Introduction}

Pleasure in-others'-misfortune is a phenomenon well known to people of all times, as well as its antonym - sympathy or indifference "located" between them. Although this pleasure has never been a source of pride, today it seems to be regarded as more inappropriate than in the days of our distant ancestors. ${ }^{1}$ On the other hand, because of the growing self-awareness of our culture, we are now more open to free from prejudice consideration of sources, functions and the moral status of this emotion.

Because of its infamous character, pleasure derived from others'-misfortune has rarely been the subject of in-depth theoretical considerations focused solely on it. It has been most commonly discussed in the context of other related emotions - compassion, envy and jealousy. Two books devoted to this emotion deserve to be distinguished: When Bad Things Happen to Other People by Johna Portmann (2000) and Schadenfreude Understanding Pleasure at the Misfortune of Others edited by Wilco W. van Dijk and Jaap W. Ouwerkerk (2014). The first of the highlighted publications is a philosophical analysis of pleasure in-others'-misfortune in the context and discussions with the views of philosophers such as Aristotle, Schopenhauer and Nietzsche. The other is an interdisciplinary ${ }^{2}$ edited volume devoted to the presentation of the current state of research on this emotion. ${ }^{3}$ From the point of view of my work, three first parts of the book are the most important: Schadenfreude as a justice-based emotion; Schadenfreude as a comparison-based 
emotion and Schadenfreude as an intergroup phenomenon. The results of psychological research presented in these passages in an interesting way correspond to the approach to pleasure in others'misfortune suggested Aaron Ben-Ze'ev. However, the research by Wilco W. van Dijk and Jaap W. Ouwerkerk $^{4}$, which showed that attention to positive self-esteem is an important motive generating the experience of pleasure in others'-misfortune are the closest to my considerations of pleasure in others'-misfortune. Since the mentioned studies provide empirical support for the analysis of pleasure in others'-misfortune presented in this work I will refer to them in the next passages of my work.

The idea to consider the infamous emotion of pleasure-in-others'-misfortune in terms of possible benefits was inspired by the concept of emotions as adaptive mechanisms which was suggested by Israeli philosopher Aaron Ben-Ze'ev [2, chapter 2] and the criticism of the distinction between "positive" and "negative" emotions which functions in social sciences by American philosopher Robert Solomon's [14, Myth Six. Two Flavors of Emotion, Positive and Negative].

According to the first concept emotions are reactions to specific ("local") changes in the subject's situation aiming at adapting him to this change. In this way, situationally provoked fear is an adaptive response in the face of particular danger concentrating on remedying it, e.g. through escaping from it. In terms of the Israeli researcher emotions are also a "response" to much deeper changes, connected with the randomness of human existence, i.e. to existential changes. Ben-Ze'ev focuses on death, the most important change of this kind, for me, however, a different kind of existential change - old age is more interesting.

On the other hand, Solomon rightly pointed out that treating the opposition "positive"/"negative" as the proper criterion for the division of the entire class of emotion is a serious mistake, because this additional definition is not as straightforward as it might seem. It means that the distinction between what is positive and what is negative hides other polarizations. ${ }^{5}$ Reference of substantially various meanings of these additional definitions to emotions varied in content reveals that unequivocal qualification of a given type of emotion (or a particular emotional manifestation) from the point of view of their positivity and negativity is not possible. ${ }^{6}$

Inspired by the Ben-Ze'ev's functional approach to emotions and taking into account the equivocal valence of emotions in terms "positive"/"negative", I began to wonder what role pleasure-in-others'-misfortune could hypothetically play, which could also weaken the negative public image of that, in my opinion, very human emotion. This article arose from this idea.

In the recently conducted research on the moral nature of pleasure in others'-misfortune we can, following A. H. Fischer [4, pp. 309-310] differentiate two approaches. The first concentrates on the motives of this emotion, while in the other attention is focused on social implications of pleasure in another person's misfortune. Although both the concept of emotions (including pleasure in others'-misfortune) as adaptive mechanisms proposed by Aaron Ben-Ze'ev, and my considerations of a special kind of pleasure in others'-misfortune (pleasure in others' aging) fit in the first of the distinguished research perspectives, it does not mean that the other approach is depreciated here. Unfortunately, certain important issues related to the latter research approach do not have sufficient support in research. What I mean here is the question about potential destructiveness of pleasure in others'-misfortune. There is little research on the influence of that pleasure on its „objects” (that is, a person afflicted by a misfortune giving pleasure to some else). Although it seems a plausible presumption that an overt expression ${ }^{8}$ of pleasure in others'misfortune probably intensifies the discomfort experienced by the misfortune person, this assumption has not yet been sufficiently verified empirically. ${ }^{9}$

On the other hand, as philosopher John Portmann indicates, the destructiveness of pleasure in others'-misfortune is not necessary prejudged by the overt expression of this emotion. He maintains that people as capable of both compassion and pleasure in others'-misfortune and indifference to what happens to others, are also aware that showing compassion and hiding indifference and even more pleasure at others'-misfortune is the best insurance policy. Because this 
policy guarantees us help and support in need, we pretend sometimes that we are worried by the fate of others when it is indifferent to us and/or when we are happy because of someone's bad luck. The problem is that judging from our own attitude, we have a strong premise to suspect all other people of pretending appropriate emotions (compassion) and/or hiding inappropriate ones (pleasure in others'-misfortune). Although the assumption of universal social benevolence is considered naive, all of us in some way need to believe that other people do not wish us harm. This circumstance, I think, may be an argument supporting the assumption about the potential social destructiveness of pleasure in others'-misfortune. ${ }^{10}$

I cannot agree with Arthur Schopenhauer, who considered pleasure-in-others'-misfortune a devilish emotion, worse than alleged "human" envy ${ }^{11}$ [11, pp. 99-100], although I share certain moral distaste associated with the nature of this emotion. It is difficult to contradict Ben-Ze'ev when he writes that ,it would appear to be morally more perverse to be pleased with another person's misfortune than to be displeased with another person's good fortune" [2, p. 374]. Perhaps such bad public perception of that emotion is related to the duration attributed to it. It seems that pleasure-in-others'-misfortune is often not considered a short-term emotion (lasting seconds or a few minutes), which we could compare to an unwanted thought imposing itself like an involuntary reflex. Instead, it seems to be seen rather as a kind of excessively prolonged vindictive satisfaction with the fact that someone is in a worse situation. Such long-term pleasure may be perceived as stubborn and unchangeable, and thus it can be easily identified with a moral defect rather than (to some extent unconscious) "a moment of forgetfulness". Although the duration of specific pleasure in others'-misfortune may vary greatly, in my opinion, a short (lasting seconds or minutes) experience of this emotion is more frequent and thus more typical. ${ }^{12}$ Ben-Ze'ev emphasizing the "transient" character of pleasure-in-others'-misfortune, in contrast with envy [2, p. 377] seems to indicate, just like me, that the moral condemnation of this emotion is excessive. If, indeed, the moral qualification of that pleasure is too strict, we have a valid reason to reconsider this emotion.

For many past and modern philosophers ${ }^{13}$ the unequivocally negative assessment of this emotion is treated as a mistake. Often, like St. Thomas [15, issue 94] they focus on whether the object's misfortune was deserved by him or not ${ }^{14}$ and they treat the decision on that matter as an important criterion for the moral evaluation of the specifically occurring case of satisfaction-inothers'-misfortune. ${ }^{15}$ Similarly, an unjustified association of that emotion with cruelty is often pointed out. ${ }^{16}$ Due to the passive nature of pleasure in others'-misfortune, the propensity to harm someone or take revenge on someone should not be seen as an expression of this emotion, but rather as possible long-term consequences connected with a prior experience of pleasure at someone else's misfortune (e.g. the fall of the "tall poppy" we envy). Leaving this issue in my work I concentrate mainly on cases of pleasure in others'-misfortune which cannot be justified by the fact that the subject deserved what happened to him. For me a special and perhaps not as rare as you might wish case of that pleasure is pleasure in someone else's aging. This study is devoted to the consideration of this specific variant of pleasure-in-others'-misfortune in terms of the adaptive function of the emotion.

This article consists of two main parts: the first, in which I present Ben-Ze'ev's concept of emotions as adaptive mechanisms and the second, in which I first briefly introduce Ben-Ze-ev's characteristics of pleasure-in-others'-misfortune and then consider hypothetical pleasure in someone else's old age through the prism of the adaptive function assigned to emotions.

\section{Adaptive Function of Emotions}

The idea that emotions have an adaptive function is a concept developed in modern evolutionary psychology in which it is argued that emotions are developed in the course of evolution programs organizing the behavior of the subject, focused on his survival [5, chapter 7]. Aaron Ben-Ze'ev refers to the above precise definition. In his view, emotion is a phenomenon caused by the 
perception of a significant change in the subject's situation, aimed at the adaptation of the person to the change. Changes taking place in the external and or internal environment of the subject demonstrate the instability of his life position. And this instability can be potentially detrimental to him. Emotions, as a kind of an early warning system, not only signal that something needs attention, but also intensify the attention and temporarily narrow the cognitive perspective of the subject.

In the context of survival of the individual a change for the worse seems to be more important in the relations person-environment. This does not mean, however, that only this "kind" of change generates emotions, understood as adaptive mechanisms. According to Ben-Ze'ev:

Emotions typically occur when we perceive positive or negative significant changes in our personal situation - or in that of those related to us. A positive or negative significant change is that which significantly interrupts or improves a smoothly flowing situation relevant to our concerns [2, p.13].

In the proposed approach to emotions it is stressed that a change is essential not only for emotions, but also for human consciousness as such. It is clear that when the situation of the body is stable (no change is taking place), it goes into a state of limited consciousness, called "an automatic pilot". In this state, similar to the unwitting maintenance of vital functions which constantly takes place in every living organism, the performance of routine, everyday tasks (such as getting dressed, cooking, etc.) is basically automatic, and therefore does not require the involvement of consciousness. This means that the subject "switched" to auto pilot is in some measure sensorially, perceptually and cognitively asleep, and his consciousness unconcentrated on the occurring change is passive and uninvolved. Just like Ben-Ze'ev we can treat this decrease in awareness as "constituting a process of adaptation (...) which expresses the system's return to its homeostatic state" [2, p. 15].

Unlike changes essential for consciousness in general, changes that cause emotions have a highly personal meaning. Changes which the subject perceives as having significant implications for him or those who are connected with him have this status. It is stressed that a change relevant to the generation of emotions is "a perceived change whose significance is determined by us" [2, $\mathrm{p}$. 16]. Moreover, the perceived change can be either a change which actually took place or only an imagined one. Both types of changes are essentially subjective, because it is the perceiving subject who decides that changes are significant for him. Apart from the importance of the changes he determines their extent, because deciding to include chosen persons to the group of beings that have a personal meaning for him he sets the range of his emotional involvement (response).

In Ben-Ze'ev's terms emotions are not only a reaction to "local", specific changes in the subject's situation. They are also a "response" to a more profound kind of change associated with the randomness of human existence, i.e. an existential change. I will define the first kind of change with the adjective "external" and the other as "internal". It would be convenient to assume that the former have a real, and the latter mostly imaginary character. Such an assumption is, however, not justified due to the heterogeneous nature of the concept of "existential change". Although BenZe'ev writes about one form of this change - death - not only possible death "persists" in the background of human existence, affecting certain emotional reactions of the subject. ${ }^{17}$ It seems that the term "existential change" can include also: maturation, aging, chronic illness, as well as entering into new social roles, e.g. of a parent, a spouse or a senior. Each of the above-mentioned "forms" of the existential change can pertain to the perceiving subject and/or people who are important for him. Possible own or someone else's death, as an indelible element of the situational context, has primarily an imaginary character due to its potentiality. The same can be said about other types of existential changes as long as they are only possibilities which are taken into account. The situation changes when these possibilities actually occur - someone close dies, the subject or someone close to him is ill/maturing/aging or enters into a new role. The death of a loved one is a one-time fact, while maturation, aging, illness or performing of a new role are processes extended in time. The 
processual nature of these phenomena is responsible for the way they are perceived. The ailing, maturing or aging subject cannot deny the reality of the changes that occur in him. On the other hand, he cannot completely ignore those which will occur. The subject must adapt to the two types of changes (the occurring ones and the future, and thus only imagined ones). Just like Ben-Ze'ev, I maintain that it is possible thanks to emotions.

\section{Comparative Character of Emotional Concern}

According to Ben-Ze'ev the occurrence of emotions is determined by a significant change, i.e. the one which the subject regards as relevant from the point of view of his personal concerns (interests, worries). "Concerns" are defined here as "short- or long-term dispositions to prefer particular states of the world or of the self" [2, p. 18]. Emotions serve to monitor and safeguard these personal concerns. The author additionally defines the typical emotional involvement by reference to such aspects as: a) comparative character, b) the availability of an alternative, c) social comparison and d) group membership.

Ad a)

Ben-Ze'ev stresses that "significance, or meaning, is by nature relational; it presupposes order and relations" [2, p.18]. The significance of relations for the meaning which the subject assigns to the change is compared here to the rank which color has for the sense of sight. Color is a necessary condition of seeing, but of course not the entire contents of perception. The implication of the relational nature of significance is its comparative nature. Understanding of something involves, therefore, the comprehension of its alternative.

Opting for the comparative character of emotions Ben-Ze'ev maintains that:

the emotional environment contains not only what is, and what will be, experienced but also all that could be, or that one desires to be, experienced; for the emotional system, all such possibilities are posited as simultaneously there and [as such - MMJ] are compared with each other [2, p. 19].

It is clear that the comparison is important because of the central role of changes in the generation of emotions. Only in comparison with a certain background structure the given event may be perceived as a significant change. This structure can be described as a personal baseline. In this way, the reason to feel envy would be a higher position of the object in relation to the subject's personal baseline. Analogously, pity or contempt would be emotions towards those whose position was estimated as significantly below one's personal baseline. Shame would be the result of perceiving own behavior as grossly below own normative standards determined by this baseline, and pride would be the result of estimating it to be significantly above them.

According to Ben-Ze'ev the personal baseline expresses a person's values and attitudes. It is a specific resultant of biological, social, personal, and contextual features. It is also a flexible ${ }^{18}$ and not rigid structure, which we can adapt to our own experience, determining the way in which we perceive our own (but also others') states - present, past, ideal and desirable. Emotions are formed by comparing one's own new present situation to one's own different situation or of significant others. Own or someone else's "different" state, as a standard of assessment of the current position, can be a real earlier state, an ideal state in which one wishes to be, or a state in which one should be. In short, an emotion is a result of the discrepancy between one's own (or someone else's) new position and this person's personal baseline, which is a real/ideal/normative criterion that determines the kind of felt emotions. In light of the above, sadness and happiness are the result of a comparison of one's current state with his earlier condition. In contrast, disappointment, hope, fear, 
love, hate, sexual desire and disgust are to be related to a comparison of the present condition with the ideal state. On the other hand, comparing one's own position with the current situation of others may lead to other emotions such as envy, jealousy, pity, compassion, happiness because of the wellbeing of others or pleasure-in-others'-misfortune. Certain emotions can be the result of several kinds of discrepancies occurring at the same time. In Ben-Ze'ev's opinion these are anger and gratitude because these emotions are often connected with a comparison of the current condition of the subject not only with his previous position but also with the condition desired by him, i.e. the one in which, according to his judgment, he should be.

One of the implications of the characteristic for emotions comparative assessment of the situation of the subject or people close to him is that they go beyond the given information. The emotion generating change can be real or imagined. Both are the result of a comparison.

Perceiving the significance of an actual change involves its comparison with some imagined alternatives; and imagining an alternative involves a comparison with our present situation. Perceiving actual changes entails a comparison of our current situation with our normal, baseline situation: the more significant the change is perceived to be, the more intense the emotion [2, p. 20].

Sometimes the real and imaginary types of changes are in conflict. One can be, for example, satisfied with winning a small prize (three winning numbers in a lottery) and at the same time dissatisfied because of perceiving oneself as someone who has not won a lot more (six winning numbers).

Ben-Ze'ev maintains that:

Actual and imaginary changes are present in all emotions, but their relative importance varies. In negative emotions, where our evaluation of the situation is negative, the imaginative type is usually more dominant since the preferred reality is imagined. However, imagination is also present in positive emotions (...) it is dominant in hope and in sexual desire (...) Humans do not live exclusively in the immediate present. Through our mental capacities, we imagine what is likely to happen, what already happened, or what might happen [2], p. 21].

It seems, therefore, that in the case of human emotions, they are mainly the result of "perception" of imagined changes.

Ad b)

An important element of a comparison constituting the emotional significance is a mental construction of an alternative situation. The greater availability (or proximity) of that imagined alternative results in a more intense emotion because: "A crucial element in emotions is, indeed, the imagined condition of <<it could have been otherwise>>, [2, p. 21]. What has just been written explains why in games like ,all or nothing" the proximity of an unachieved success ${ }^{19}$ is more frustrating than failure itself. When the teams playing the match clearly differ in their level of skill a close loss of the underdog can be a source of pride, instead of sadness, felt by its fans. Not only the greater proximity of an alternative, but also its lack intensifies the felt emotion. Ben-Ze'ev notices that outright failure may lead to depression because the defeated subject cannot imagine a better alternative. A situation in which no particular alternative is more likely to occur than others is also emotionally significant. It happens because of increased uncertainty, which is a variable of emotional intensity.

Ben-Ze'ev notes that the notion of the availability of an alternative is connected with the concept of "abnormality". This is because an "abnormal" (deviating from the norm, not ordinary) event has a highly available alternative. What is more, "the more exceptional the situation, the more available the normal alternative and the more intense the emotion" [2, p. 23]. 
Emotions arise not only as a result of the perception of a significant change in the physical environment of man, but also (if not primarily) due to the perception of a significant change in his social environment. In the latter case, an emotion is a result of social comparison. This comparison, in general, refers to people and areas which the given subject considers relevant for his own wellbeing or for the most important concerns. Ben-Ze'ev stresses that in social comparison we do not compare only our own current state with the state in which the significant others are. One's present state is also juxtaposed with one's own earlier state, with the ideal state and the desired state from the point of view of a recognized duty.

Our perception of these states - especially of the ideal and "ought" states - are heavily dependent on social norms and the way others perceive them. Social comparison is important in determining our values and hence our emotions; it reduces uncertainty about ourselves and is helpful in maintaining or enhancing self-esteem [2, p. 24].

For these reasons, social comparison is a potential source of personal instability, especially in terms of self-esteem. An example of the latter is a situation in which the mere presence of someone with very desirable traits produces a decrease in one's self-esteem and thus creates negative emotions.

Social comparison has a decisive role in a number of emotions, among others in envy, jealousy, pleasure-in-others'-misfortune, compassion, gratitude, hatred, anger, embarrassment, pride and shame. ${ }^{20}$ The importance of social comparison in such emotions as fear or hope is less obvious. In Ben-Ze'ev's opinion these emotions are more concerned with existential matters. ${ }^{21}$

The importance of social comparison for the generation of emotions is connected with various kinds of relationships. For emotions the most important are social relations that include rivalry and cooperation, and conformity and deviation. Rivalry and cooperation characterize relations among individuals. In contrast, conformity and deviation can be measured in relation to certain values. Rivalry prevails in envy and pleasure-in-others'-misfortune. In these emotions, satisfaction and dissatisfaction depend on the relative superiority of the subject in comparison with the object of the emotion. On the other hand, cooperation prevails in compassion and love as these are emotions directed towards the well-being of both the subject and the object of the emotion. Conformity and deviation dominate in guilt, regret, gratitude, anger, hatred, pride and shame because all these emotions are focused on the compliance of our or others' behavior with certain standards.

In the pair of terms: conformity vs. deviation, deviation is more significant in the context of generating emotions because it attests to the occurring change.

\section{Ad d)}

Another very important factor in the emotional reactivity is group membership. If we agree with Ben-Ze'ev that emotions are focused on the issue of survival and social status then one will need to recognize their (emotions') dependence on the formation of groups. Two types of groups have particular importance for emotions: social groups and the reference group.

Every human group is a more or less organized collection of individuals collectively sharing certain standards and entering in relationships with one another. Members of the group are significantly interdependent. Due to this interdependence group membership (e.g. in the family, economic class, ethnic, religious, professional or political party group) essentially influences the goals, self-esteem and well-being of the individual. Against the background of the above definition of the term "group", the types of groups stressed by Sen-Ze'ev - the social group and the reference group - require further additional specification. A particular social group to which the person 
belongs is composed of persons with whom this person has frequent social contacts and real social relations. A function of such a group is to provide mutual support and close social ties to each of its members. Typically, it is less organized and less binding than the reference group, so it can include people with whom we do not have hierarchical relationships. Although generally the social group is larger than the reference group it does not have to contain all its members. Such a situation occurs when we do not have social contact with some members of the reference group.

Someone's reference group contains all those with whom that person compares himself. Members of this group are the most essential for achieving the objectives of the person comparing with them and for his self-esteem. Someone's reference group can include those whom that person knows personally and those with whom he has only imagined, not real, relations. Therefore, the reference group plays a large role in defining the attitudes which its members maintain and appreciate. It also affects the shape of norms and rules which they consider binding regulators of their own behavior. The significance of the reference group is reflected in the fact that the individual identifies with it or aspires to belong to it. The reference group is a kind of a normative censor/controller of attitudes and behaviors of its members, determining their group status. The individual status in the reference group can change significantly in time, while it is generally stable in the social group. The stability of the membership status in the social groups prevents social isolation, whereas the membership in the reference group prevents normlessness which may result in the loss of personal identity.

They above highlighted types of groups are connected with different emotions. Envy, pleasure-in-others' -misfortune, hatred, shame and pride are derivatives of the rivalry prevailing in the reference group and self-esteem of its members which is constantly threatened (or at least demands confirmation). Other emotions are typically triggered by the membership in the social group. The relative status of each member of this group is of less importance than in the reference group. However, the actual situation of individuals is of great importance. For these reasons, the membership in the social group contributes to the occurrence of the emotions of compassion, happy for, fear, hope and love. In contrast, emotions typical for both these groups are, according to BenZe'ev, anger and gratitude. It is justified by the fact that these emotions include concern for our self-esteem in the group.

It is often difficult to set a demarcation line between someone's social group and his group of reference. In the case of children it is typical that both groups overlap, because children do not have fully formed self-esteem, and thus individually specified boundaries. In adults, the borders of the two groups are to some extent flexible. They depend on the way in which one sees his relationships with people in his environment. It is easier to change the boundaries of the social group than the boundaries of the reference group.

It is more up to us to determine with whom we have social contacts than to determine who is significant within the areas of importance to us (...) it is difficult to avoid comparing our professional status and achievements with a colleague who is superior to us (...) however, that sometimes we change the borderlines of our reference group as a result of our personal development or to protect ourselves from frustration and other negative emotions [2, p. 28].

\section{Adaptive Nature of Pleasure-in-Others'-Misfortune ${ }^{22}$}

Ben-Ze'ev refers everything that is written above about the nature of emotions to all emotions, and thus also to the emotion of pleasure-in-others'-misfortune. In the following part of this article I will focus on the issue of beneficialness of this emotions for the subject experiencing it. Meanwhile, I will introduce the reader to the characteristics of this emotion presented by Aaron Ben-Ze'ev [2], pp. 353-377]. 
According to Ben-Ze'ev, the cases of the occurrence of the emotion of pleasure-in-others'misfortune are typically accompanied by the following circumstances, which are also its peculiar characteristics:

1. The person who is the object of this emotion is perceived by the subject as deserving what happened to him;

2. His misfortune is relatively minor ${ }^{23}$;

3. The subject is passive in generating the object's misfortune [2, p. 356].

I do not fully agree with the above additional specification of pleasure-in-others'-misfortune. I actually fully approve only of the third circumstance highlighted by Ben-Ze'ev'a associated with the occurrence of pleasure-in-others'-misfortune. Substantially:

An active personal involvement is contrary to the rules of fair competition (...) [because it is - MMJ] deliberately harming the other (...) [that is why the subject would not be able to feel - MMJ] the real winner in the ongoing competition [2, p. 359].

In other words, an important feature of feeling joy because of adverse fate of another person is the fact that his bad luck is a kind of "unwelcome gift from fate". This feature lets us distinguish this emotion from sadism and cruelty which are sometimes identified with it. In addition, "the subject's innocence" gives him some kind of right to feel pleasure because of this unwelcome gift. According to this principle we do not rebuke joy of a finder of someone's lost property, although we know that its owner came to harm.

Basically I also agree with the second characteristics of pleasure-in-others'-misfortune. Indeed, generally pleasure-in-others'-misfortune pertains to relatively small misfortunes. Ben-Ze'ev is right when he considers the fact of rejoicing at someone else's tragedy (the death of a child, etc.) as an atypical and abnormal case unfortunately associated with this emotion. On the other hand, currently old age is often portrayed as a great misfortune, sometimes more frightening than death. Does this mean that cases of joy felt due to observable aging of another person should be classified as symptoms of pathology? Not necessarily. The analysis of this special kind of pleasure-inothers'-misfortune in terms of the adaptive function assigned to emotions will show (I hope) that its concrete occurrence is not necessarily a dangerous deviation from the commonly acceptable standard.

I cannot, however, agree with the first additional definition of pleasure-in-others'misfortune proposed by Ben-ze'ev. Although I think that presenting this emotion as allegedly inhuman is wrong, it seems equally inappropriate to me to treat it as a virtue, which happens when pleasure at someone's misfortune is justified by the fact that it was deserved. In this approach the deservedness of a specific misfortune not only legitimises the "onlooker's" pleasure, but is also supposed to testify to his moral motive - the assumed concern for justice. John Portmann accurately notes that although the satisfaction derived from the suffering of others (e.g. those convicted of murder) "might stem from an objective concern for justice (...) [there is still doubt - MMJ] about the frequency of that kind of morally acceptable pleasure" [8, pp. 199-200]. I think it is often not about justice. ${ }^{24}$ It happens that the motive is a desire to compensate one's own shortcomings or suffered failures. If we accept Portmann's argument that ,we are more likely to view the misfortunes of others as deserved than we are our own" [8, p. XI], then we will have to accept that the correct classification of the misfortune that happens to someone else under the terms indicated here (the deservedness) can be problematic. ${ }^{25}$

Another issue is the scope of meaning attributed to the emotion of pleasure-in-others'misfortune. I think that limiting this scope to the cases of pleasure-in-others'-deserved misfortune, as suggested by Ben-Ze'ev, is wrong. I think that the reduction of the incidence of this emotion to a situation where someone's misfortune is deserved, thereby giving us the legitimacy to rightfully enjoy it $^{26}$ is not correct. Similarly, the position of Aristotle [1, $1233 \mathrm{~b}$, pp. 452-453], who reduced 
this emotion to pleasure in someone else's undeserved misfortune, while calling rejoicing at deserved misery - righteous indignation ${ }^{27}$, seems excessively reducing. In other words, pleasure-inothers'-misfortune seems to include pleasure in both deserved and undeserved bad luck of another person.

Ben-Ze'ev's claim that "the very fact of being pleased with someone's misfortune implies our belief that this misfortune is somehow deserved" [2, p. 357] seems true in a specific way. It seems that this specific truthfulness lies in the fact that not finding the reason for someone's bad luck and at the same time feeling joy because of its existence we are actively looking for its justification, often going so far as to pseudo-rationalization. It happens not only because most of us have inculcated impropriety (and even immorality) of pleasure-in-others'-misfortune. An important motive for the search for a reason for the occurrence of someone else's misfortune is the fear of it, and the desire to repress that fear. ${ }^{28}$ This reason, I suppose, is typical for the emotions of pleasurein-others'-aging.

If we maintain that pleasure-in-somebody's-aging is an adaptive reaction we need to immediately ask what change it is to adapt the subject to. I suggested that it is a change of existential nature - one's own future or just started aging. Unlike death (another form of an existential change), which is a single fact, aging ${ }^{29}$ is a process. This circumstance is responsible, in my opinion, for the perception of this change. ${ }^{30}$ Many people are afraid of old age because our culture depreciates it. Old age is identified with infirmity, ugliness, dependence on others, and generally with the lack of significance. Elderly people are not noticed and "not respected". The world is no longer theirs. If indeed it is so, it is not surprising that own aging is the object of strong repression. Young people repress the awareness of their future old age simply by not accepting it as a fact. It is easy, because for a young person his own old age is as abstract as disease is for a healthy person. A middle aged person is in a more difficult situation. Although we can treat life as the aging process stretching over time, it is clear that the apparent "swallows" of changes associated with aging occur only in the so-called middle age (around 40 years of age). At that time it is difficult to deny the reality of the changes that occur in us, or completely ignore those that are to come. That is why, achieving this level of maturity seems to generate the highest level of fear of old age. If it is so, this stage of ontogenetic development is the most conducive to pleasure-in-other's-aging if we assume that this emotion really adapts the subject to his own (occurring or future) aging.

If, according to Ben-Ze'ev's concept, a change significant from the point of view of the subject initiates an adaptive response - emotion - we have to assume that the higher intensity of this change, the greater the strength of the emotion. Translating this into the aging process, we can say that the more rapidly the process takes place, the greater the fear it causes, due to which the adaptation to the observed change becomes a more urgent task. On the other hand, it seems that people differ in the reactivity or approach to changes taking place inside and outside. Although it is necessary do adapt to every change, it can be experienced in various ways. What I want to say is that such a radical change as aging does not have to cause fear in every person. It probably pertains to those of us who are more distanced to both the media demonizing of the old age and to the cultural overestimation of youth. I leave it to the reader's consideration where this distance comes from. In short, we cannot say that aging is an absolutely threatening change that causes a specific emotion, e.g. fear of or pleasure at someone else's old age.

For the sake of clarity I confine the analysis of the emotion of pleasure-in-other's-aging to the consideration of women's fear of old age and hypothetical woman's pleasure-in-other's-aging. If fear has a gender it seems that the fear of losing physical attractiveness is central in the female fear of aging ${ }^{31}$. Treating this hypothetical assumption as legitimate, I limit myself to considering the emotion of pleasure-in-other's-aging to women's rejoicing at signs of deteriorating physical appearance observed in another woman. ${ }^{32}$

In our times, "there are no ugly women, there are only neglected ones", and that is why women seem to feel obliged to be physically attractive. Old age itself is treated today in a similar 
way, i.e. more as a matter of negligence, rather than the effect of the inevitable biological process. We are told that we work the whole life for our old age, thus suggesting that as a result of acting properly (diet, exercise, caring) our own old age will not be ugly, infirm or insignificant. In short, we are taught that culture can overcome biology. If this is true we are responsible for what we look like in mature and older age. On the other hand, despite the fact that maintaining pretty appearance is presented as a realistic task, it is known that it is like winning the Tour de France - an extraordinary achievement, accomplished in competition with all those who have the same goal.

Comparison of efforts to maintain attractive appearance to the competition highlights the importance of determinants of emotions indicated by Ben-Ze'ev - comparison, the availability of an alternative and the reference group. I will show below how all of them contribute to the occurrence of specific woman's joy due to the reduced attractiveness of another woman.

Keeping Ben-Ze'ev's findings, I treat women's pleasure in another woman's physical attractiveness deterioration due to age as a result of comparison. What is compared here is one's own attractiveness and attractiveness of another woman. Although the impulse to felt pleasure is someone else's worse appearance, it is not, as Ben-Ze'ev argues, the subject of this pleasure. This emotion concerns obtaining a higher status (here: attractiveness) and not humiliation of the "rival", although this ,ennoblement" requires her diminution. According to Ben-Ze'ev's analysis of pleasure-in-others'-misfortune in the enjoyment of someone's lesser attractiveness we should see also a reaction to the imagined change. This means that this emotion is also the result of a comparison of the current good looks of the subject for example with the imagined (past or future) looks of another woman. ${ }^{33}$

An important element of a comparison constituting the emotional significance is a mental construction of an alternative situation. Greater availability of this imagined alternative is to correspond to greater intensity of the felt emotion, because in emotions the imagined condition - "it could be otherwise" - has great importance. In light of this, pleasure in someone else's deteriorating appearance will be more intense when the imagined alternative - own reduced attractiveness - is more accessible. Such a situation occurs when a woman of our age or a younger one looks worse than we. The similarity of the subject's age to that of the object of the emotion (here: a peer/a younger woman) is for the subject a threatening memento activating fear of what is to come - the reduced attractiveness of own appearance. The assumed increased intensity of the emotion due to greater availability of the alternative corresponds to my assumption that middle age especially predisposes people to pleasure in somebody's old age.

A comparison, which results in an emotion (including: pleasure in someone else's lesser physical attractiveness) is primarily a social comparison, i.e. relating to people and areas important from the point of view of well-being and the most important concerns of the subject. What is more, social comparison is multidimensional, so feminine joy because of another woman's worse appearance is the effect of not only comparing the current appearance of the subject with the appearance of the ,rival". This emotion arises also by comparing one's own present appearance with the earlier, ideal and desirable (in the sense of being an expression of a specific duty) attractiveness. Ben-Ze'ev emphasizes that our perception of the above distinguished own states is largely dependent on social norms and how others perceive us. Hence, social comparison is important in determining our values and affects subjective self-esteem. Applying these findings to women's pleasure due to the lower attractiveness of another women, we can say that: 1 . This joy is a by-product of our culture characterized by the perception of women in which physical beauty of women is overrated. 2. An important attribute of feminine beauty is youthful appearance. Maintaining it is an ideal which women try to achieve in different ways and in varying scopes. 3 . Women feel obliged to ensure that their appearance corresponds to the current standards of beauty. How well (and if at all) they fulfill this ,task" affects their self-esteem. 4. Reduced attractiveness of a peer/a younger woman confirms the beauty of the one who compares herself to her. For this reason, women may be inclined to feel pleasure in decreasing beauty of other women. 
The reference group, including all those with whom the subject compares herself, also plays a considerable role in "provoking" pleasure-in-others'-misfortune. Since we compare ourselves with those who are the most essential for our purposes and self-esteem, the reference group determines our status. According to Ben-Ze'ev's analysis feminine pleasure in the deteriorating appearance of another woman is the result of rivalry and constantly threatened self-esteem in the reference group with which the woman feeling this pleasure identifies herself and to which she aspires. It can be assumed that the reference group of an average 40-year-old woman includes not only peers, or more broadly her generation (e.g. women born in the 70s), but also women from the later generation, that is from 10 to 15 years younger. What is more, each reference group includes not only those people with whom the subject has actual contact, but also women personally unknown to her - actresses, singers, etc. - who often have opportunities to maintain and preserve their beauty which are unattainable for ordinary women. It is clear that these unusual members of one's reference group increase the physical attractiveness standard binding in this group. Oddly often mediocre women, identifying with the reference group, do not blame them, because slowly and nicely aging celebrities prove that the maintenance of attractive appearance is achievable for anyone who tries hard enough. Assuming that this is the case makes it easy to absolve oneself of experienced pleasure in worse appearance of a female friend. The former can "rationalize" that it is the latter's fault - she has not kept a diet, has not exercised, has not nurtured her skin, etc. Blaming a female friend for her condition we protect ourselves from compassion for her. When the woman sympathizes with another woman because of the visible traces that time has left on her, then in a way she identifies with her, and thus takes into account the fact that today's misfortune of the other woman can befall her tomorrow. ${ }^{34}$ The identification with the object, which is characteristic for compassion, may thus undermine the sense of one's own efforts to maintain beauty.

Why should we be afraid of compassion if it confronts us with the brutal truth that the desire to maintain attractive looks is like chasing a rabbit? The answer is contained in the question itself, because it is the brutal truth, and as such should be applied in doses. If we cannot win it means that we are like others, dependent on biology, not exceptional as general Zajączek's wife who being an elderly lady aroused appreciation for their beauty of young men in their twenties. Does the above mean that the fear of own old age should always be alleviated? An affirmative answer does not seem to be correct. Trivially speaking with the passage of time it becomes more and more difficult to maintain appealing appearance, and thus it becomes increasingly difficult to believe in its maintenance. What is needed in the face of changes that cannot be denied is the adaptive acceptance of them.

In light of the above, women's pleasure in the deteriorating physical attractiveness of anther woman can be seen as a necessary part of gradual adaptation of the subject to her own, not remote in time/recently started aging process. If this possibility is plausible, a tendency to feel that kind of joy should decrease with the progress of the physical changes associated with own aging. Should this assumed "predisposition" also disappear? I think that it should. This cannot be applied, however, to pleasure-in-other's-aging understood more broadly, i.e. not limited only to physical changes in appearance. I signaled earlier that as the aging process progresses its other attributes gain in importance. Saying the obvious: to maintain health and fitness becomes the most important. ${ }^{35}$ Competing in the realm of health seems bizarre, and also inappropriate. Although unhygienic lifestyle and/or applied diet are often the main (and sometimes the only) cause of a disease, a disease seems to be still seen primarily as something that happened to a particular person, and not as an ailment that the patient himself is culpable of. A disease perceived in this way is not a suitable object for pleasure in someone else's aging. ${ }^{36}$ The situation is different in the case of physical fitness. It seems that regardless of gender, all elderly people may have a tendency to feel pleasure in someone else's deteriorating physical fitness, as long as they believe that physical fitness is a result of exercising. This belief not only justifies their joy, but also allows for the temporary repression of fear of one's own infirmity. As such it is the affirmation of their own power. 


\section{Conclusion}

In light of the above presented depiction of emotions as adaptive mechanisms, emotional sensitivity is the resultant of the subject's specific ability to face two kinds of changes - "local" and existential changes. Ben-Ze'ev emphasizes that, thanks to the reactive character, emotions can be seen not only as a testament to individual sensitivity, but also as an expression of profound vulnerability of the subject. On the other hand, we can also perceive them as "ways to cope with [this vulnerability MMJ]" [2, p. 17].

It means that an emotional response in the face of a specific local change in someone's situation may be a way to cope with what really cannot be overcome - the most important existential change, our own death. In other words: 1 . An emotional reaction in the face of a certain change is synonymous with granting significance to it; 2 . This assigning of significance to a local change is a form of ignoring a change responsible for our existential vulnerability (death); 3 . This "ignoring" is a kind of self-deception, "a certain measure of [which - MMJ] (...) is highly advantageous from an evolutionary point of view, as it enables us to protect our positive self-image and mobilize the required resources for facing daily changes" [2, p. 17]. ${ }^{37}$

It is clear that the assigned to emotions ability to face a local change in the situation of the subject only seemingly reduces his existential vulnerability. This disposal should not, however, be depreciated. Thanks to emotions life itself seems possible. By engaging the subject in the activity aiming at his adaptation to everyday changes which are identified as important, they give meaning not only to the effort overcoming them, but also to the very existence focused on constantly repeated actions of this type. As Ben-Ze'ev rightly observes, without emotional involvement which affirms ordinary changes "the fact that in the long run all of us will die" would have to imply that in the short term we should not strive to "forget" that it is the case, i.e. to live, in the sense of constantly adapting to the changing environmental conditions [2, p. 17]. In short, by motivating us to respond to changes around us and in us emotions give us the illusion that we can overcome death because the most important reason for our reaction to changes is our will to survive. And this seems to be exactly the final sense of the specific kind of pleasure-in-others'-misfortune - pleasure-inothers'-aging.

\section{References}

1. Arystoteles. Etyka Eudejmejska. In. Arystoteles. Dzieła wszystkie. Vol. 5. Transl. by W. Wróblewski. Wydaw. Nauk. PWN: Warszawa, 1996.

2. Ben-Ze'ev, A. The Subtlety of Emotions. MIT Press: Cambridge, 2000.

3. Feather, N. T. Deservingness and schadenfreude, pp. 29-57. In. W. W. Van Dijk, J. W. Ouwerkerk (eds.). Schadenfreude. Understanding Pleasure at the Misfortune of Others. Cambridge University Press: Cambridge, 2014.

4. Fischer, A. H. Schadenfreude, concluding notes, pp. 304-311. In. W. W. Van Dijk, J. W. Ouwerkerk (eds.). Schadenfreude. Understanding Pleasure at the Misfortune of Others. Cambridge University Press: Cambridge, 2014.

5. Kuipers, G. Schadenfreude and social life: a comparative perspective on the expression and regulation of mirth at the expense of others, pp. 259-294. In. W. W. Van Dijk, J. W. Ouwerkerk (eds.). Schadenfreude. Understanding Pleasure at the Misfortune of Others. Cambridge University Press: Cambridge, 2014.

6. Levis, M., Haviland-Jones, J. M. (eds.). Psychologia emocji. GWP: Gdańsk, 2005.

7. Oostdijk, D. "Smile not, however, I venture to repeat": schadenfreude in nineteenth-century American literature, pp. 292-303. In. W. W. Van Dijk, J. W. Ouwerkerk (eds.). Schadenfreude. 
Understanding Pleasure at the Misfortune of Others. Cambridge University Press: Cambridge, 2014.

8. Ouwerkerk J. W, Van Dijk W. W. (eds.). Intergroup rivalry and schadenfreude, pp. 186-199. In. W. W. Van Dijk, J. W. Ouwerkerk (eds.). Schadenfreude. Understanding Pleasure at the Misfortune of Others. Cambridge University Press: Cambridge, 2014.

9. Portmann J. When bad things happen to other people. Routledge: London, 1999.

10. Rusaczyk, M. (ed.). Teoria opanowywania trwogi. Dyskurs $w$ literaturze amerykańskiej. Wydaw. Nauk. „Scholar”: Warszawa, 2008.

11. Schopenhauer, A. O podstawie moralności. Transl. by Z. Bassakówna. Wydaw. „bis”: Warszawa, 1994.

12. Schurtz, D. R., Combs, D., Hoogland, Ch., Smith, R. H. Schadenfreude in sports and politics: a social identity perspective, pp. 170-185. In. W. W. Van Dijk, J. W. Ouwerkerk (eds.). Schadenfreude. Understanding Pleasure at the Misfortune of Others. Cambridge University Press: Cambridge, 2014.

13. Smith, R. H., Thielke, S. M., Powell, C. A. J. Empirical challenges to understanding the role of envy in schadenfreude, pp. 91-109. In. W. W. Van Dijk, J. W. Ouwerkerk (eds.). Schadenfreude. Understanding Pleasure at the Misfortune of Others. Cambridge University Press: Cambridge, 2014.

14. Solomon, R. True to Our Feelings. What Our Emotions Are Really Telling Us. Oxford University Press: Oxford, New York, 2007.

15. Św. Tomasz z Akwinu. Suma teologiczna. Vol. 34, Rzeczy ostateczne. Transl. by P. Bełch P. Katolicki Ośrodek Wydawniczy „Veritas”: Londyn, 1986.

16. Van Dijk, W. W., Ouwerkerk, J. W. Striving for positive self-evaluation as a motive for schadenfreude, pp. 131-148. In. W. W. Van Dijk, J. W. Ouwerkerk (eds.). Schadenfreude. Understanding Pleasure at the Misfortune of Others. Cambridge University Press: Cambridge, 2014.

17. Van de Ven, N. Malicious envy and schadenfreude, pp. 110-117. In. W. W. Van Dijk, J. W. Ouwerkerk (eds.). Schadenfreude. Understanding Pleasure at the Misfortune of Others. Cambridge University Press: Cambridge, 2014.

\section{Notes}

1. Such a presumption arises after reading the texts by Kuipers [4] and by Oostdijk [7]. Kuipers shows changes that have taken place in social regulations relating to pleasure in-others' -misfortune. These changes have been the result of transformations in the sphere of contemporary standards of civilized behavior. In the Middle Ages it was not thought that pleasure connected with watching the suffering or even death of publicly punished criminals is immoral. However, in later times reacting with this emotion in the face of someone else's misfortune was not only inappropriate, but also immoral. Oostdijk proves that by the incorporation of new, more civilized rules of showing emotions to the nineteenth-century novels (e.g. The Portrait of a Lady and The Adventures of Huckleberry Finn) these books "incidentally" educated the readers to slow their emotional "savage" impulses by empathically feeling the situation of other people.

2. Apart from philosophical texts contained in this volume (e.g. by Aaron Ben-Ze'ev and John Portmann), there are also studies in the field of psychology, sociology and history of literature.

3. This book contains a summary of the state of research on the emotion of pleasure in others' -misfortune in issues such as the definition of that emotion, its moral nature, factors determining the occurrence of pleasure in others' misfortune, the role of this pleasure in group and intergroup relations, the expression of this emotion and its social consequences, etc.

4. The description of these studies is contained in the second part (in the ninth chapter) of the mentioned collective volume[16]. 
5. Solomon enumerates nineteen different additional definitions of the terms "positive"/"negative", while stressing that his "list" is not complete. For example the sense of the term "positive" covers, among others: 1. That is good (in the sense that it satisfies my needs and / or my desires), 2. That gives me pleasure, 3. That makes me happy, 4. That is good in the normative sense, i.e. connected with the observance of certain universal principles and rules,5. Positive attitude to object, 6. Positive attitude to self, 7. The object has high status, 8. I have high (higher) status. In contrast, meanings of the term "negative" indicated by Solomon are, of course, oppositions of the definitions of the adjective "positive" [14, pp. 171-172].

6. Solomon mentions only simple disgust as a possible exception to this rule. You can, however, have doubts whether this disgust is an emotion or simply a physiological, automatic reflex.

7. I put the word "object" in inverted commas because the object (i.e. the subject) of pleasure in others' -misfortune is not the unhappy person, but his/her misfortune, and even (if we agree with A. Ben-Ze'ev) own, free from that bad luck state of the person manifesting this pleasure.

8. For example, in the form of naughty, overt laughter.

9. That hypothesis seem in some way confirmed by the study conducted by A. H. Fischer, Mann, et al in 2014 which showed that the audience laughing at someone offended causes a stronger feeling of humiliation in that person [4, $\mathrm{p}$. 310].

10. On the other hand, pleasure in others' -misfortune may be a factor strengthening the unity of a group. This happens when members collectively experience and express their joy at the misfortune of members of the group with which they compete (e.g. fans of a sports team). In such a situation this joy not only strengthens ties in their own group, but essentially does not harm intergroup relations, because it promotes "healthy competition". Unfortunately, when the balance of power between the rival groups is apparently uneven, that healthy competition, which in some sense expresses respect for the rival, can be replaced by ruthless, aggressive domination. Then joy at the failure of the other group (especially collectively and publicly expressed) can have destructive consequences for the self-esteem of the victim (the defeated group) [12], [7].

11. The exact wording of the quote to which I refer is as follows: "Feeling envy is human, gloating over the misfortunes of others is diabolical. There is no sign more infallible of an entirely bad heart, and of profound moral worthlessness than open and candid enjoyment in seeing other people suffer". Although we are talking here about envy, it pertains rather to envy. The description of alleged jealousy contained in the fragment of the paragraph from which this quote comes justifies that conclusion. [Note from the translator: in the Polish version of the book the word used in this fragment is jealousy, not envy].

12. I base this assumption on the fact that in childhood we are taught that pleasure-in-others' -misfortune is not only inappropriate, but also immoral and possibly imprecating punishment for the one who feels it. "You will be punished if you take pleasure in someone's misfortune". Thanks to this teaching, many of us are ashamed of it when we feel this emotion (and hence we do not disclose experiencing this emotions) and/or preventively avoid it, in the same way as we avoid cursing someone in fear of our curse turning against us. For these reasons, the subject experiencing this emotion seems to have a tendency to shorten the duration of this experience and/or to deny it. In short, as a result of the received education we chide ourselves for feeling pleasure-in-others'-misfortune, that is why this emotion seems to be rather "spot" felt.

13. For example, for St. Thomas Aquinas, I. Kant, John Portmann or Aaron Ben-Ze'ev.

14. Numerous psychological studies show that the more deserved someone else's misfortune is, the higher the level of pleasure felt by the observer of the other parson's suffering [3].

15. John Portmann is a known contemporary philosopher emphasizing the importance of the deservedness of the object's misfortune for the moral evaluation of the joy at his misfortune. He points that that the pleasure that one derives from the suffering of another person (if suffering is adequate to his guilt) "might stem from an objective concern for justice". In this case, it is a morally acceptable kind of pleasure. Portmann distinguishes this morally justified joy at someone else's misfortune from the condemned "malicious glee" (pleasure motivated and constituted by malice). Malicious glee, despite its fundamentally unethical nature, can be justified if the other person's misfortune is deserved or trivial, and the malicious person enjoying it is passive (in the sense of not causing this misfortune) [8], pp. 199-200]. On the other hand, the same author indicates that the issue the deservedness of the misfortune is very problematic. More information about this will be discussed later in this paper, on the occasion of the presentation of Ben-Ze'ev's clarification of pleasure in-others' -misfortune. 
16. John Portmann's book [8], contains an interesting discussion about various kinds of criticism of pleasure-in-others' -misfortune.

17. The great importance of fear of death for the emotional functioning of man is stressed by the creators of the TMT (terror management theory) - J. Greenberg, S. Solomon, T. Pyszczynski. They point out that people are generally so afraid of their own death that they are highly motivated to repress the awareness of this future fact from their consciousness. An effective way of this repression of this fear is not noticing or belittling (instead of compassion) someone's suffering or a tragedy happening to other people [10].

18. Ben-Ze'ev rightly pointed out, however, that "such flexibility (...) is limited since our ability to change our values and attitudes is limited" [2, p. 19].

19. Such a situation occurs, for example, when the level of the teams playing the match is even.

20. Researchers such as Smith [12], Schurtz [12], Van de Ven [17] or Van Dijk [16] similarly to Ben-Ze'ev emphasize the central meaning of social comparisons for a particular instance of pleasure in-others' -misfortune.

21. "Fear of death and hope for better health are such cases in which the concern for our existence is so dominant that social comparison is less significant. In other cases of fear and hope, social comparison may be significant" [2, p. 24].

22. In the strict sense, this emotion is rather pleasure/enjoyment/joy caused by someone's failure/bad luck, which is suggested in 2).

23. Although it may seem easy to distinguish the trivial from the serious misfortune, the explicit qualification of what befell the other person can often constitute a problem. John Portmann writes about it inspired by the view of Arthur Schopenhauer according to which trivial misfortunes do not exist and therefore all suffering should be treated equally seriously, instead of laughing at it, or even worse enjoying it. Portmann rejects the attitude of seriousness and compassion towards every possible misfortune postulated by Schopenhauer. On the other hand, he also stresses that "it is impossible to draw a clean line between trivial and non-trivial suffering" [8, p. XVII].

24. I have in mind justice in the Kantian sense, i.e. something impartial, which is different from the rationalized selfinterest.

25. The correct classification of a given misfortune into the class of deserved or undeserved ones is difficult for many reasons. Using John Portmann's interesting analysis of this question [8, Introduction) I will show only two of them: 1. An obvious reason for the ease with which we accept someone else's suffering is our self-interest. Nietzsche showed how easy it is to "see" a bad person in an individual with whom we compete for a certain good. In this way, the rival, as someone bad, deserves the misfortune that befalls him. 2. Beliefs regarding what people deserve, widespread in the given culture and time, are always in some way arbitrary and potentially harmful. To simplify, one could say that in the eighteenth century United States, according to white people black slaves deserved their fate. In the same way, a heterosexual, conservative community condemning promiscuity and/or sex between men can perceive people with visible signs of syphilis or suffering from AIDS as individuals who deserve the disease. If such an estimation took place, those who made it are, according to Portmann, "bad things that happened to others who suffer". In short: the determination of someone's misfortune as "deserved" is not a simple ascertainment of the real state of affairs, but rather an act of its constitution.

26. Also St. Thomas Aquinas' explanation of saints' joy when observing the deserved suffering of the wicked seems similarly reductive.

27. "Envy means being pained at people who are deservedly prosperous, while the emotion of the malicious man is itself nameless, but the possessor of it is shown by his feeling joy at undeserved adversities; and midway between them is the righteously indignant man, and what the ancients called Righteous Indignation-feeling pain at undeserved adversities and prosperities and pleasure at those that are deserved".

28. This human motive is described in an interesting way by the psychological terror management theory. This reason is also the essence of one of the attributes of defense - the belief in a just world.

29. Just like maturation, suffering from an illness or entering into new social roles.

30. I think that the perception of aging and maturing, entering into new roles or developing a chronic illness must also be a process. We perceive these phenomena, so to speak, in tranches. Maybe that is why we can accept them. On the other hand, the fact that signs of aging develop gradually in a long-term perspective (several years/decades) facilitates the repression of the occurring aging process from consciousness.

31. The loss of beauty is something that excludes women from the competition for importance and influence. An old woman does not mean much, because no one notices her. An exception to this rule are only women who are 
outstanding in their field/very well known. Oddly, many of them maintain attractive appearance, thus confirming the social practice of marginalization of unattractive women.

32. This does not mean that women do not feel the fear of all that is associated with/attributed to old age - infirmity, dependence on others or lack of significance. It just concerns the fact that for a 40 or 50 year old woman infirmity and the other above mentioned attributes of old age are as abstract as old age is for a very young person.

33. Trivially speaking a comparison with the imagined past appearance of another person is a necessary condition to be able to recognize his/her present appearance as a significant change. A comparison of one's own attractiveness with the imagined deteriorating physicality of another woman is less obvious. If such a comparison occurs, it makes the significance of the actually observed change more frightening (e.g. the loss of skin elasticity or face oval) perceiving it not so much as a single symptom of deteriorating appearance associated with old age, but rather as an obvious harbinger of something much worse - the total loss of beauty. In short: the imagined change intensifies fear of old age, and thus increases pleasure-in-others' -misfortune as the one which the subject has (yet!) succeeded to avoid.

34. It is a reference to one of the conditions of compassion highlighted by Aristotle - similarity of possibilities.

35. I am not writing here about intellectual ability, because mental indisposition of various degrees is connected with serious diseases, while reduced fitness (except, of course, post-traumatic disability, or resulting from the nature of the disease someone has suffered from) is simply the result of negligence of efforts aimed at maintaining one's own body in good shape.

36. I have pointed out that I believe that the reduction of cases of pleasure in someone's misfortune to deserved failures is inappropriate, however a disease seems to be some exception. In the case of an illness, particularly a severe and chronic one, Ben-Ze'ev's emphasis on the deservedness of the misfortune that happened to the other person (cf. the first of the additional definitions of pleasure at someone else's misfortune distinguished by Ben-Ze'ev) seems to be justified. Perhaps the assumed unique status of a disease stems from the fact that it is (especially when it is serious) generally perceived as great evil. A disease seen in this way, in accordance with the second of the characteristics of pleasure-in-others' -misfortune proposed by Ben-Ze'ev, is not a typical object of this emotion.

37. Remedying a local change in one's own situation proves agency, and it is an important component of self-esteem. In this way, a person forced to move by his own fear has a sense of agency and control over his own live if his escape from the aggressor was successful. 